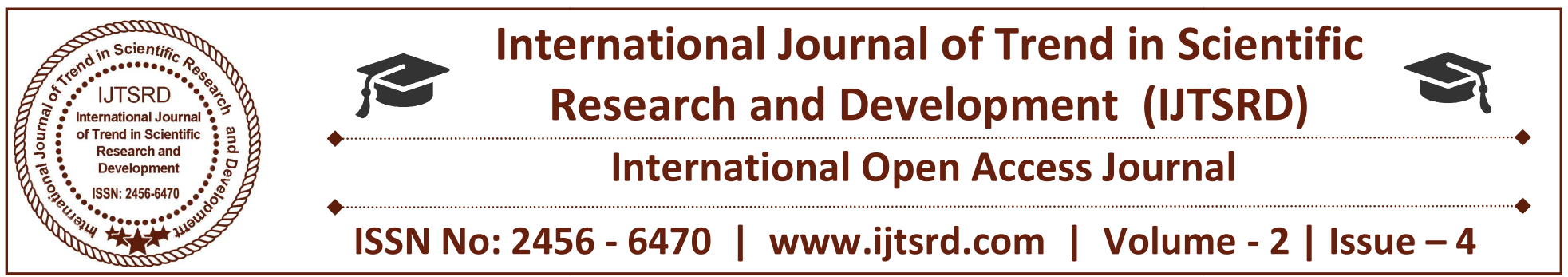

\title{
Extraction, Stability \& Storage of Punica Granatum L. Peel Extract
}

\author{
Akanksha Samuel ${ }^{1}$, Yogita Dobhal ${ }^{2}$ \\ ${ }^{1}$ Assistant Prof, ${ }^{2}$ Assistant Prof \\ ${ }^{1}$ Smt. Vidhyavati Group of Institutes Goramachhiya, Jhansi, Uttar Pradesh, India \\ ${ }^{2}$ Sardar Bhagwan Singh Post Graduate Institute, Balawala, Dehradun, Uttrakhand, India
}

\begin{abstract}
The aqueous extract of Punica granatum L. peel was prepared by basic one-step liquid-liquid extraction. The extraction method involved partitioning $10 \% \mathrm{v} / \mathrm{v}$ water in methanol extract of the peel between ethyl acetate \& $2 \%$ aqueous acetic acid. This specific extraction process increases the ellagic acid content by approximately double $\mathrm{w} / \mathrm{w}$. furthermore, the antioxidant activity is evaluated by the DPPH, radical scavenging assay, which tends to increase ED50 roughly by triple the value $\mu \mathrm{g} / \mathrm{ml}$. these stability evaluations were measured under several conditions \& temperatures, over a couple of months with successful results. The factors like humidity, sunlight, temperature fluctuations etc were all experimented during the stability test. Whereas, the acidity $(\mathrm{pH})$ of the extract was the only loop-hole making it unstable in the aqueous or syrup (semi-solid) condition. Hence, the chemical constituent in the extract was stabilized when the extract was kept in amorphous, dried (powder) state.
\end{abstract}

Keywords: punica granatum L., ellagic acid, DPPH, peel extract

Introduction- Pomegranate (Punica garanatum L.), of family Punicaceae, fruit peel is the waste material/by-product, of the fruit juice industry, which is a rich source of hydrolysable tannins belonging to ellagitannin family. The fruit peel has been discovered to possess higher chemical constituents than the fruit itself. There are various clinical applications of Punica granatum L. fruit peel in the medicine industry, such as, treatment \& prevention of cancer, chronic inflammations, which are believed to play an essential role etiologically, as suggested (Lansky \&

Newman,2007). The other uses include cosmetics (Aguilar et al., 2008), nutraceuticals etc.

The ellagic acid content is basically a marker for standardization of the fruit/fruit peel extract (Zhou et al.,2008) \& even serves as a bio-marker of the chemical constituent consumed with the help of bioavailability in the plasma, after consumption (Seeram et al., 2004). Ellagic acid holds the key to various other uses, anti-inflammatory (Ogawa et al., 2002), anti-allergy (Rogerio et al., 2008), anti cancer (Larrosa et al., 2006) (Mertens-Talcott \& Percival, 2005), anti-microbial (Zambuchini et al., 2008), antitesticular toxicity (Turk et al., 2008) \& last but not the least anti-toxicant in case of phosholipase $\mathrm{A}_{2}$ toxicity (Da Silva et al., 2008). The maximum content of Ellagic/acid is obtained by simple purification method, liquid-liquid extraction to prepare an ellagic acid rich punica granatum L. peel extract. The product needs to be stabilized due to ellagic acid's unstable nature. It degrades in sunlight, moisture, $\mathrm{pH}$, temperature changes etc.

\section{Materials \& methods-}

Plant material: The punica granatum L. variety being native to the areas of India \& Iran, were not subjected to any identification or authentification. The sample was collected from the native fields directly. The peels were dried at $50^{\circ} \mathrm{C}$ for approximately 24 hours in a hot air oven. The peels aren't allowed to be dried under sunlight, due to degeneration issues of ellagic acid content of the peel. The dried material was grinded \& passed through the sieve no. 45 . 
Chemicals \& reagents: Std. Ellagic acid by Sigma Aldrich, DPPH (1,1-diphenyl-2-picrylhydrazyl) by Rankem, Methanol (HPLC grade), Acetic acid \& Ethanol (analytical grade) by Rankem. Water distilled/purified by Milli Q system (ultra pure).

Preparation of Punica granatum L. peel extract: The grinded powder of the peel $(0.5 \mathrm{~kg})$, extracted with methanol in $10 \% \mathrm{v} / \mathrm{v}$ water $(2 \mathrm{~L})$ under reflux for 1 hour $(\times 2)$. The extract collected was dried in the vacuo. Then $(4 \mathrm{~g})$ extract, suspended in $2 \%$ aq. Acetic acid $(400 \mathrm{ml})$, is then partitioned with ethyl acetate $(400 \mathrm{ml} \times 4)$, to maintain a desired $\mathrm{pH}$ level. The extract finally collected was in ethyl acetate fractions, which was further evaporated into a dry mass in vacuo.

\section{Quantitative analysis-}

HPLC conditions \& calibration curves: Agilent 1100 series with PDA \& auto-sampler was used in HPLC evaluation. (PDA: photo diode array detector). The $3 \mathrm{D}$ chem.station software, analyses the data in which the separation was achieved at $25^{\circ} \mathrm{c}$ on $150 \mathrm{~mm} \times 4.6 \mathrm{~mm}$ TSK gel ODS-80Tm column. Mobile phase consists of methanol $\& 2 \%$ aqueous acetic acid with $0-15 \mathrm{~min}, 40-60 \% \mathrm{v} / \mathrm{v}$ methanol \& 15-20min, $60 \% \mathrm{v} / \mathrm{v}$ methanol (gradient mode elution), at a flow of rate $1 \mathrm{ml} / \mathrm{min}$. the injection infused is $20 \mu \mathrm{L}$, whereas wavelength is set at $254 \mathrm{~nm}$. The curve is calibrated with respect to the std. ellagic acid at 3$50 \mu \mathrm{g} / \mathrm{ml}$. The linear equation of $\mathrm{Y}=139159 \mathrm{X}+26.146$ $\left(r^{2}=0.9995\right)$ corresponding to the ellagic acid.

Sample preparation: $5 \mathrm{mg}$ of extracts were taken \& diluted by methanol to make up the volume up to $10 \mathrm{~mL}$, accurately measured with the help of a volumetric flask. The solution was then filtered through $0.45 \mu \mathrm{m}$ membrane filter. The final product is then subjected to an HPLC analysis.

In vitro antioxidant assay: The antioxidant assay using DPPH free radical scavenging method was determined in fractions (Yamasaki et al., 1994). The stock solution $(1 \mathrm{mh} / \mathrm{ml})$ of the sample is prepared in absolute ethanol. There are five different concentrations maintained by two-fold dilution. Now, $0.1 \mathrm{~mL}$ of the sample was mixed with $6 \times 10^{-5} \mathrm{M} \mathrm{DPPH}$ in absolute ethanol. The mixture is allowed to stand for approx $30 \mathrm{~min}$ at room temp., covered in aluminum foil. The absorbance is measured at $520 \mathrm{~nm}$, on a spectrometer. The scavenging activity of the sample was calculated by: DPPH radical scavenging $\%=(1$-absorbance of sample/absorbance of control $) \times$ 100. A mixture of absolute ethanol $(500 \mu 1) \& 6 \times 10^{-5}$
M DPPH in absolute ethanol $(500 \mu \mathrm{L})$ is used as control. Now, the DRC (dose response curve) is plotted by inhibition \& concentrations. A linear regression analysis was carried out by calculating the effective concentrations of the sample required by the $50 \%$ of the DPPH radicals, which is $\mathrm{EC}_{50}$. Ellagic acid \& quercetin is used as positive control here. All the tests were carried out as a pair of three readings.

\section{Stability evaluation-}

Light: The 100mg of peel extract was weighed \& stored in an air tight container, kept in a room at temperature $30^{\circ} \pm 2^{\circ} \mathrm{C}$ ), one sample exposed to sunlight \& one protected from sunlight, for four months. An aliquot of each sample was taken at $0,1,2,3,4,6,8,12$ and 17 weeks. This is subjected to qualitative \& quantitative analysis of the main chemical constituent using HPLC. The readings were taken as a pair of three each.

Temperature: The $100 \mathrm{mg}$ of peel extract was weighed \& stored in an air tight container, kept in a room at temperature $\left(30^{\circ} \pm 2^{\circ} \mathrm{C}\right) \& 4^{\circ} \pm 2^{\circ} \mathrm{C}$, protected from sunlight, for four months. An aliquot of each sample was taken at $0,1,2,3,4,6,8,12$ and 17 weeks. This is subjected to qualitative \& quantitative analysis of the main chemical constituent using HPLC. The readings were taken as a pair of three each.

Accelerated conditions: The 100mg of peel extract was weighed \& stored in an air tight container, kept in a room at temperature $45^{\circ} \mathrm{C}$ at $75 \%$ humidity, protected from sunlight, for four months. An aliquot of each sample was taken at $0,1,2,3,4,6,8,12$ and 17 weeks. This is subjected to qualitative \& quantitative analysis of the main chemical constituent using HPLC. The readings were taken as a pair of three each.

pH (acidity): The 100mg of peel extract was weighed \& stored in an air tight container, dissolved in phosphate buffer solution to achieve $\mathrm{pH}$ value of 5.5, $7 \& 8$, kept in a room at temperature $\left(30^{\circ} \pm 2^{\circ} \mathrm{C}\right)$, protected from sunlight, for four months. An aliquot of each sample was taken at $0,1,2,3,4,6,8,12$ and 17 weeks. This is subjected to qualitative \& quantitative analysis of the main chemical constituent using HPLC. The readings were taken as a pair of three each. 
Statistics: Values are expressed as mean \pm SD. Data was analyzed by student t-test. The level of statistical significance was taken as $\mathrm{P}<0.05$.

\section{Results \& discussion-}

Preparation of punica granatum L. peel extract, rich in desired chemical constituent: The yield obtained by fractional pomegranate peel extract with the method of liquid-liquid extraction between ethyl acetate \& 2\% aq. Acetic acid, the ellagic acid rich extract was $16.56 \pm 1.132 \% \mathrm{w} / \mathrm{w}$ with reference to the powdered material (table 1). The texture of the product changes from a dark brown sticky semi-solid mass to a much lighter brown powder extract. The HPLC clearly depicts the major content present was ellagic acid. This specific method increased the content of ellagic acid in the extract from $7.06 \pm 0.025 \%$ to $13.63 \pm 0.89 \% \mathrm{w} / \mathrm{w}$, along with the antioxidant activity (table 1,2) The suppression of ionization of ellagic acid in aq. acidic conditions which decreases the solubility of ellagic acid in water, is the reason ethyl acetate is used. The content measured/evaluated has an ellagic acid content of approx $13 \% \mathrm{w} / \mathrm{w}$.

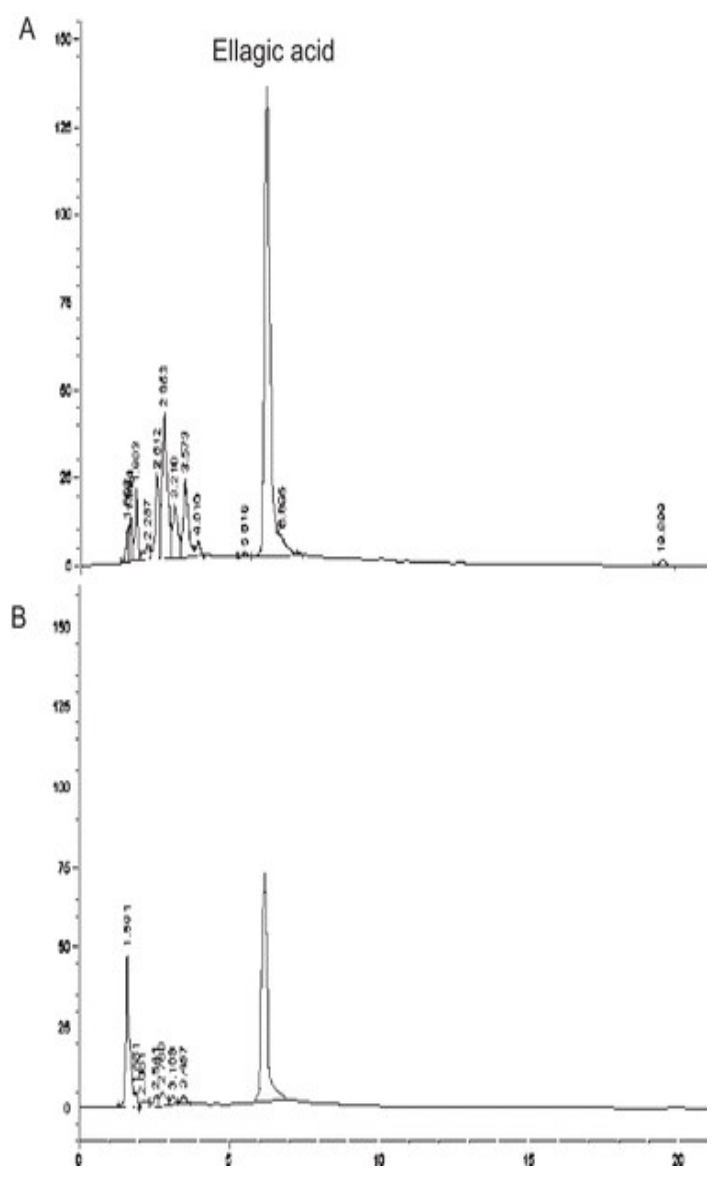

Figure 1: HPLC chromatograms of sample at $\mathrm{pH}$, initially (A) \& 10 weeks later (B).

Table 1: Punica granatum L. peel extract yields

\begin{tabular}{|l|l|l|l|}
\hline $\begin{array}{l}\text { Extracts/ } \\
\text { compounds }\end{array}$ & $\begin{array}{l}\text { Extraction yield } \\
\left(\% \mathrm{w} / \mathrm{w}^{*}\right)\end{array}$ & $\begin{array}{l}\text { Ellagic acid } \\
\left(\% \mathrm{w} / \mathrm{w}^{* *}\right)\end{array}$ & $\begin{array}{l}\text { Antioxidant } \\
\text { activity ED } \\
(\mathrm{\mu g} / \mathrm{ml})\end{array}$ \\
\hline Crude extract & $32.51 \pm 2.14$ & $7.06 \pm 0.025$ & $38.21 \pm 0.138$ \\
\hline Ellagic acid-rich extract & $16.56 \pm 1.132$ & $13.63 \pm 0.891^{\#}$ & $14.91 \pm 0.239^{\#}$ \\
\hline Standard quercetin & - & - & $3.57 \pm 0.637$ \\
\hline Standard ellagic acid & - & - & $3.12 \pm 0.349$ \\
\hline
\end{tabular}

*- compared to the weight of powdered sample, **- compared to weight of extract, \#- SD $(\mathrm{P}<0.05)$ compared to crude extract.

Table 2: Liquid-liquid extraction fractions \& the chemical constituent, antioxidant activity.

\begin{tabular}{|l|l|l|}
\hline Solvents for extraction & $\begin{array}{l}\text { Ellagic acid content } \\
(\% \mathrm{w} / \mathrm{w}, \text { mean } \pm \mathrm{SD})\end{array}$ & $\begin{array}{l}\text { Antioxidant } \\
\text { activity, } \\
(\boldsymbol{\mu} / \mathrm{m} / \mathrm{m} \text {, mean } \pm \text { SD) }\end{array}$ \\
\hline Ethyl acetate \& water & $9.24 \pm 0.511$ & $16.31 \pm 0.722$ \\
\hline Ethyl acetate \& $\%$ aq. acetic acid & $13.63 \pm 0.891^{*}$ & $14.91 \pm 0.239^{*}$ \\
\hline
\end{tabular}

$*_{-} \mathrm{SD}(\mathrm{P}<0.05)$

Stability evaluation: Ellagic acid is the rudimentary marker for stability of the extract. The studies of effect of light on the stability proved that the physical appearance was almost unchanged throughout the term of the experiment, whereas the chemical constituent content decreases slightly with time. Furthermore, the sample kept in sunlight is left with slightly lesser chemical constituent due to oxidization. 
The study on temperature changes showed no significant difference in the qualitative or quantitative analysis. Hence, the product is stable at both $4^{\circ} \mathrm{C}$ and $30^{\circ} \mathrm{C}$ as well, all along the time period of the experiment. Now, the study on accelerated conditions showed no difference at all in the physical or chemical characteristic of the product. The stability rate is estimated to be maintained for up to 2 years, if stored properly in closed containers at room temp. The acid-base stability of the punica granatum L. peel extract was tested in 5.5, $7 \& 8 \mathrm{pH}$ level. It was found that $\mathrm{pH} 5.5$ sample was yellow, $\mathrm{pH} 7$ sample was brownish yellow \& pH 8 sample was brown. The chemical constituent degrades slightly over the period of 4 months (table 3 ).

In this condition, HPLC records depicted the main peak of degraded polar compound with retention time of 1.6 min (figure 1B). The ester group of ellagic acid was hydrolyzed to hexahydroxyphenic acid in aq., acid \& base solution. The result from the following stability test proves satisfactory stability for further use \& development of the herbal medicine, in its powdered state only.

Table 3: Chemical constituent at $\mathrm{Ph} 5.5,7 \& 8$

\begin{tabular}{|l|l|l|l|l|l|l|}
\hline \multirow{2}{*}{ Week } & \multicolumn{7}{|c|}{ Ellagic acid content $(\% \mathrm{w} / \mathrm{w}$, mean $\pm \mathrm{SD})$} \\
\cline { 2 - 7 } & $\mathrm{pH} \mathrm{5.5}$ & $\begin{array}{l}\% \\
\text { remaining }\end{array}$ & $\mathrm{pH}$ & $\begin{array}{l}\% \\
\text { remaining }\end{array}$ & $\begin{array}{l}\text { pH } 8 \\
\text { remaining }\end{array}$ \\
\hline 0 & $12.81 \pm 0.669$ & 100 & $12.81 \pm 0.673$ & 100 & $12.81 \pm 0.671$ & 100 \\
\hline 1 & $12.82 \pm 0.408$ & 100.08 & $12.68 \pm 0.533$ & 98.99 & $12.59 \pm 0.809$ & 98.28 \\
\hline 2 & $12.71 \pm 0.189$ & 99.22 & $12.76 \pm 0.614$ & 99.61 & $12.68 \pm 0.513$ & 98.98 \\
\hline 3 & $12.59 \pm 0.808$ & 98.28 & $12.62 \pm 0.523$ & 98.52 & $12.76 \pm 0.582$ & 99.61 \\
\hline 4 & $11.02 \pm 0.321^{*}$ & 86.03 & $12.02 \pm 0.838^{*}$ & 93.83 & $11.92 \pm 0.367^{*}$ & 93.05 \\
\hline 6 & $11.89 \pm 0.512^{*}$ & 92.82 & $11.15 \pm 0.789^{*}$ & 87.04 & $10.03 \pm 0.177^{*}$ & 78.3 \\
\hline 8 & $10.41 \pm 0.484^{*}$ & 81.26 & $9.77 \pm 0.4111^{*}$ & 76.27 & $9.31 \pm 0.432^{*}$ & 72.68 \\
\hline 10 & $7.01 \pm 0.314^{*}$ & 54.72 & $8.21 \pm 0.573^{*}$ & 64.09 & $7.29 \pm 0.514^{*}$ & 56.91 \\
\hline 12 & $4.21 \pm 0.332^{*}$ & 32.86 & $7.66 \pm 0.728^{*}$ & 59.8 & $3.93 \pm 0.831^{*}$ & 30.68 \\
\hline 14 & $4.09 \pm 0.708^{*}$ & 31.93 & $7.65 \pm 0.424^{*}$ & 59.72 & $3.17 \pm 0.518^{*}$ & 24.75 \\
\hline 17 & $2.69 \pm 0.361$ & 21 & $3.29 \pm 0.253^{*}$ & 25.68 & $2.57 \pm 0.447^{*}$ & 20.06 \\
\hline
\end{tabular}

*- $\mathrm{P}<0.05$ compared with content initially.

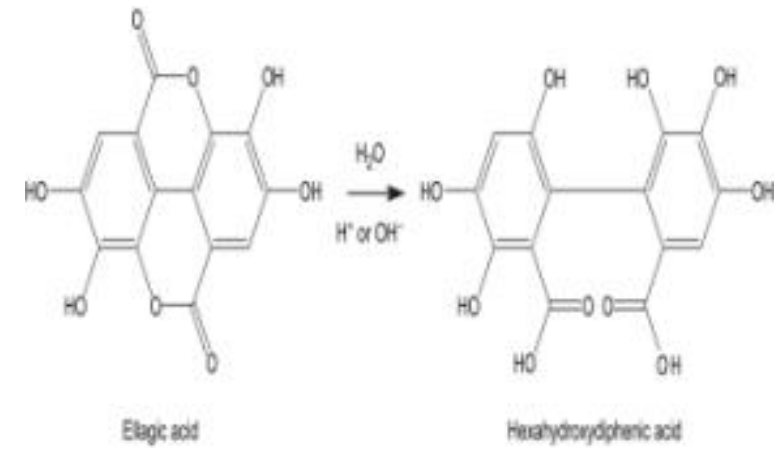

Figure 2: Hydrolysis of ellagic acid

Acknowledgements: Highly obliged to, Sardar Bhagwan Singh Post Graduate Institute of Biomedical Sciences \& Research, Dehradun, Uttrakhand. (Affiliated by Uttrakhand Technical University).

Declaration of interest: No conflict of interest to be reported.

\section{References:}

1) Zhou B, Wu Z, Li X, Zhang J, Hu X (2008): Analysis of ellagic acid in pomegranate rinds by capillary electrophoresis and high-performance liquid chromatography. Phytochem Anal 19:86-89

2) Zambuchini B, Fiorini D, Verdenelli MC, Orpianesi C, Ballini R (2008): Inhibition of microbiological activity during sole (Solea solea L.) chilled storage by applying ellagic \& ascorbic acids. LWT-Food Sci Technol 41:1733-1738.

3) Aguilar CN, Aguilera-Carbo A, Robledo S, Ventura J, Belmares R, Martinez D, RodriguezHerrera R, Contreras J (2008): Production of antioxidant nutraceuticals by solid state cultures od pomegranate peel \& creosote bush (Larrea tridentate) leaves. Food Technol Biotechnol :218222.

4) Da Silva L,Calgarotto AK, Chaar JS, Marangoni S(2008): Isolation \& characterization of ellagic 
acid deriviatives isolated from Casearia sylvestris SW aq. extract with anti PLA2 activity. Toxicon 52:655-666.

5) Lansky EP, Newman RA(2007): Punica granatum $\&$ its potential for prevention \& treatment of inflammation \& cancer. $J$ EthnopharmacoL 109:177-206.

6) Larrosa M, Tomas-Barberan FA, Espin JC (2006): The dietary hydrolysable tannin punicalagin releases ellagic acid that induces apoptosis in human colon adenocarcinoma. Caco-2 cells by using the mitochondrial pathway. J Nutr Biochem. 17:611-625.

7) Mertens-Talcott SU, Percival SS(2005): Ellagic acid \& quercetin interact synergistically with resveratrol in the induction of apoptosis and cause transient cell cycle arrest in human leukemia cells. Cancer Lett 218:141-151.

8) Ogawa $Y$, Kanatsu K, Iino T, Kato S, Jeong Y, Shibata N, Takada K, Takeuchi K (2002): Protection against dextran sulfate sodium induced colitis by microspheres of ellagic acid in rats, Life Science 71: 827-839.

9) Rogerio AP, Dontanari C, Borducchi E, Keller AC, Russo M, Soares EG, Albuquerque DA, Faccioli LH (2008): Anti-inflammatory effects of Lafoensia pacari \& ellagic acid in a murine model of asthama. Eur J Pharmacol 580:262-270.

10) Seeram NP, Lee R, Heber D(2004): Bioavaiability of ellagic acid in human plasma after consumption of ellagitannins from pomegranate. Clin Chim Acta 348: 63-68.

11) Turk G, Atessahin A, Sonmez M, Ceribasi AO, Yuce A (2008): Improvement of cisplatin induced injuries to sperm quality, the oxidant antioxidant system \& the histological structure of the rat testes by ellagic acid. Fertil Steril 89:1474-1481.

12) Yamasaki K, Hashimoto A, Kokusenya Y, Miyamoto T, Sato T (1994): Electrochemical method for estimating the antioxidative effects of methanol extracts of crude drugs. Chem Pharm Bull 42:1663:1665. 